\title{
Suspected cow's milk allergy in everyday general practice: a retrospective cohort study on health care burden and guideline adherence
}

\author{
Sharayke C T A van den Hoogen ${ }^{1}$, Alma C van de Pol ${ }^{1 *}$, Yolanda Meijer ${ }^{2}$, Jaap Toet ${ }^{3}$, Céline van Klei $^{4}$
} and Niek J de Wit ${ }^{1}$

\begin{abstract}
Background: Cow's milk allergy (CMA) is the most common food allergy among infants. No data are available on the health care burden of suspected CMA in general practice. This study was conducted to evaluate the burden of suspected CMA in general practice (GP): (a) prevalence, (b) presenting symptoms, (c) diagnostic process, (d) guideline adherence, and (e) dietary measures.

Methods: A retrospective cohort study was carried out in four Julius Healthcare Centers (JHCs). These JHCs form the core primary care academic network of the department of general practice of the University Medical Center of Utrecht. Electronic records of the first year of infants born May 2009 - April 2010 registered in the JHCs were screened for possible CMA suspicion. Preventive child healthcare $(P C H)$ records were reviewed for additional information. Clinical presentation, diagnostic strategies and dietary measures were extracted.

Results: Of 804 infants evaluated, 55 presented with symptoms fitting the suspicion of CMA (prevalence of 7\%). Presenting complaints involved the skin (71\%); the gastrointestinal tract (60\%); the respiratory tract (13\%) or other symptoms (36\%) and 23 infants presented with symptoms of two or more organ systems. In 31 children (56\%) a food challenge was performed ( $n=28$ open and $n=3$ double-blind). Open challenge test results were difficult to interpret due to inadequate implementation or reporting. None had confirmed CMA after an adequate challenge test. Long term milk substitute formulas were prescribed in 39 (71\%) infants.
\end{abstract}

Conclusion: On a yearly basis seven percent of children visit their GP for suspected CMA. A positive CMA diagnosis was rarely established after adequate implementation and reporting of diagnostics, yet long term dietary measures were prescribed in $>70 \%$ of patients. There is definitely need for improvement of diagnosing CMA in primary care.

Keywords: Food hypersensitivity, Primary care, Prevalence, Diagnostic, Guideline adherence

\section{Background}

Cow's milk allergy (CMA) is the most common food allergy among infants with prevalences ranging from $<1 \%$ (skin prick testing, blood tests and/or food challenges are used for diagnosis) to $3.5 \%$ (parent reported) [1,2]. In primary care in the Netherlands the recommended diagnostic work-up for children with suspected CMA at the time of our study was an open food challenge

\footnotetext{
* Correspondence: A.C.vandePol-5@umcutrecht.nl

'Julius Center for Health Sciences and Primary Care, University Medical Center Utrecht, Room Str 6.131 Postbus 85500, 3508 Utrecht, GA, The Netherlands

Full list of author information is available at the end of the article
}

(OFC), before starting long term diet. The consecutive steps of an OFC are described in detail in the current guideline "Food Hypersensitivity" issued by the Dutch College of General Practitioners (2010) [3]: elimination phase, provocation phase, and re-elimination of cow's milk. When symptoms disappear after elimination, appear again after provocation, and subsequently disappear again after re-elimination a positive diagnosis of CMA is established. The preceding guideline on CMA (1995) was similar to the current one, yet the OFC procedure was described more generally [4]. In secondary care, a diagnosis is made by double-blind placebo controlled food challenge testing (DBPCFC) which is the gold standard in 
diagnosing a food allergy [5]. Last year, a new multidisciplinary guideline has been issued by the Dutch Association of Pediatrics, and insight in adherence to the former guideline may help identify room for improvement when implementing new recommendations [6].

Currently, the number of patients treated for CMA is presumably two to three times higher than justified [7]. An (unjustified) CMA diagnosis may have major impact both medically (somatisation, dietary deficiencies, growth delay etc.) [3,4,7] and economically (1500-2500 Euros per suspected patient in the first year after initial presentation $[8,9])$. In the Dutch primary health care system management of suspected CMA is a shared responsibility by the GP and the preventive child healthcare $(\mathrm{PCH}) . \mathrm{PCH}$ is the Dutch national local health service whose role is routinely performing well-child visits throughout the first four years of life.

This paper tries to tackle a question raised in the NICE clinical guideline 116 (February 2011) [10]: What is the prevalence of suspected food allergy in children presenting to primary care? A suspected diagnosis is likely to be much more prevalent than (partially) confirmed CMA [2], as this is the nature of forming a diagnosis in primary care. Adequate work-up and follow-up policy for suspected CMA is important to make sure long term dietary measures are only taken for children that will benefit. We set out to determine the health care burden of infants suspected of CMA including prevalence, clinical presentation, diagnostic work-up, dietary measures and the national guideline adherence.

\section{Methods}

\section{Design}

Retrospective cohort study.

\section{Setting}

The study was conducted in the four Julius Healthcare Centers (JHCs), primary care health centers with 35.000 patients and 23 GPs. JHCs form the core primary care academic network of the department of general practice of the University Medical Center of Utrecht. The patient population largely resembles that of the average Dutch population, although the under 18 population is somewhat larger: $30 \%<18$ years old as compared to $20 \%$ for the wider Utrecht region [11]. Since other characteristics such as education level and ethnicity distributions are similar [11], we believe that the younger population in our area makes it even more suitable for primary care research projects regarding children. The primary and preventive health care system in the area under study is comparable to the rest of the Netherlands. Routine patient data are registered electronically since more than 10 years, using ICPC codes for diagnosis. During this study period the ICPC-1 codes were used instead of the recent published ICPC-2-E codes. GPs were trained in systematic data registration.

\section{Patients}

The study population consisted of infants born between May 2009 and April 2010 registered in one of the four JHCs serving Leidsche Rijn. Leidsche Rijn is a rapidly growing new suburban area in the city of Utrecht in the Netherlands. In the surveyed period almost 70\% of the residents of this district were of native origin. The large majority finished a secondary (25\%) or academic (55\%) education. Three quarters (75\%) had paid work. Most resident had a high score on personal and social wellbeing [11].

\section{Definition}

Suspected CMA was defined as: (a) recording of "a suspicion of CMA" in the healthcare record, and/or (b) implementation of CMA diagnostics and/or (c) implementation of CMA dietary measures (milk substitute formulas).

\section{Ethics}

According to the Medical Ethical Research Council of our institution, there was no need for patient consent/ethical approval for this anonymous retrospective chart review.

\section{Data collection}

Electronic records of GP consultations were retrieved to identify infants with suspected CMA in two steps. Since CMA (suspicion) is not an existing ICPC-1 code [12] we used a list of codes (symptoms of e.g. skin, respiratory tract, digestive tract; Table 1) to identify infants that had visited with complaints that could possibly fit a suspicion of CMA and subsequently reviewed their anonymous consult information to see whether CMA was indeed suspected (see definition above). Second, $\mathrm{PCH}$ records of infants with a potential suspicion of CMA were reviewed to confirm the suspicion and obtain additional information. The record-linkage of $\mathrm{GP}$ and $\mathrm{PCH}$ records was not performed by the investigator. For infants suspected of CMA the following variables were abstracted from their GP and PCH records: sex, age at onset of the suspicion, presenting complaints (skin, gastro-intestinal, respiratory, circulatory or other), diagnostic tests performed, and dietary measures. Diagnostics were defined as: a DBPCFC, an OFC and a radioallergosorbent blood test (RAST). According to the current guideline "Food Hypersensitivity" an OFC is correctly conducted when the following phases have been conducted: (a) symptoms are assessed at start of elimination and at start and end of the provocation phase (b) the test was continued for at least one week in case of mild symptoms during provocation (red stains around the mouth, crying or mild eczema) (c) the test was interpreted 
Table 1 ICPC-1 codes used to identify infants who had visited with symptoms potentially suggestive of CMA

\begin{tabular}{ll}
\hline A12 Allergy & R02 Dyspnoea \\
A14 Colics in infants & R03 Wheezing \\
A15 Excessive crying infant & R07 Sneeze, rhinitis, nasal discharg \\
A16 Irritable/hyperactive infant & $\begin{array}{l}\text { R29 Other symptoms respiratory } \\
\text { tract }\end{array}$ \\
A17 General symptoms/complaints & R96.01 Airway hyperreactivity \\
infant & R97 Allergic rhinitis \\
A29 Other general symptoms & S06 Local redness/erythema skin \\
D10 Vomiting & S07 Generalized redness/erythema \\
D11 Diarrhea & S21 Other symptoms/complaints \\
aspect skin
\end{tabular}

as positive only when original symptoms returned after provocation and again disappeared after re-elimination. For each OFC the recorded procedures for each phase were assessed to evaluate whether guideline recommendations had been followed [3]. Finally, dietary measures were recorded (types of milk formulas prescribed).

\section{Results}

\section{Population and prevalence}

In total 804 infants born from May 2009 through April 2010 were registered in the four JHCs in Leidsche Rijn of which 392 infants (49\%) visited their GP with symptoms that could possibly fit a suspicion of CMA (Table 1). After reviewing the GP's notes of these visits 64 infants were identified with a potential suspicion, and their $\mathrm{PCH}$ records were screened for additional data. Finally, 55 infants were confirmed to have a suspicion of CMA, i.e. the prevalence of suspected CMA was found to be $7 \%$ (Figure 1).

\section{Clinical presentation of suspected of CMA}

The median age of the 55 infants suspected of CMA was 14 weeks and 34 (62\%) were male. At time of presenting with a suspicion of CMA 39 of the infants had complaints of the skin (56\% eczema, 15\% urticaria or rash); 33 of the gastrointestinal tract $(22 \%$ vomiting, $24 \%$ colics, $7 \%$ diarrhea, none had constipation, $7 \%$ other: rectal bleeding or feeding problems); seven of the respiratory tract $(6 \%$ respiratory infections, $7 \%$ stridor, none had rhinitis or cough). None of the infants showed circulatory

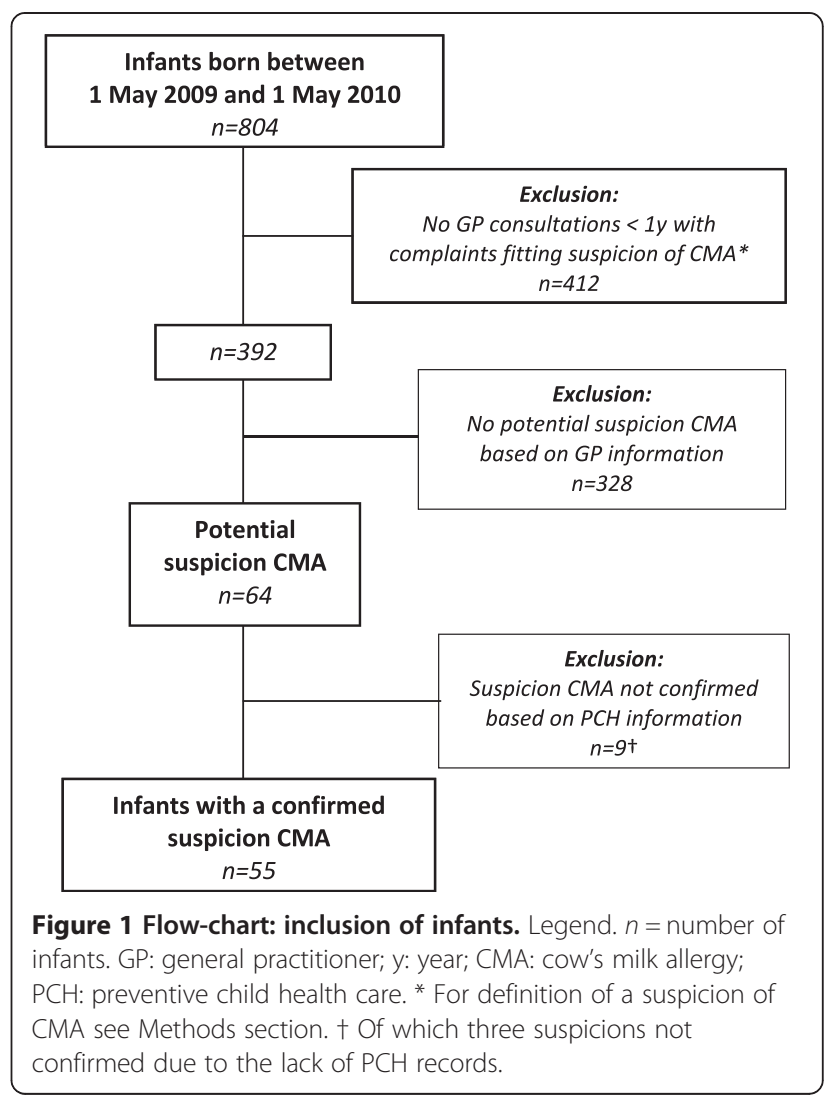

tract symptoms (tachycardia, hypotension, collapse). Twenty infants had other type of symptoms (34\% excessive crying and agitation, $2 \%$ fever). In 23 (42\%) infants, symptoms of two or more organ systems were present at the time of presentation.

\section{Diagnostic process}

\section{Type of testing performed}

In 40 of the 55 CMA suspected infants additional diagnostics were undertaken: a DBPCFC in $\mathrm{n}=3$ (all by pediatrician), an OFC in $\mathrm{n}=28(50 \% \mathrm{GP}, 39 \% \mathrm{PCH}$ professional, $4 \%$ pediatrician, $7 \%$ unknown) and a RAST in $\mathrm{n}=15$ (47\% GP, $47 \%$ pediatrician, $6 \%$ unknown).

\section{Elimination/provocation}

Of the 28 OFCs performed $n=6$ were negative. A total of $n=22$ tests were inconclusive when checked for adherence with the current guideline [3], or adherence was unclear due to inadequate reporting. Of the 22 inconclusive results six were interpreted as positive by the clinician involved. Results of the separate phases of the OFC tests are set out in Figure 2. In 8 (21\%) of the 39 infants who started with an elimination diet, it was not reported this was done in order to perform an OFC. Reasons for OFCs not being in adherence with guideline recommendations were (a) the suspicion of CMA not being substantial enough to warrant OFC [3], 


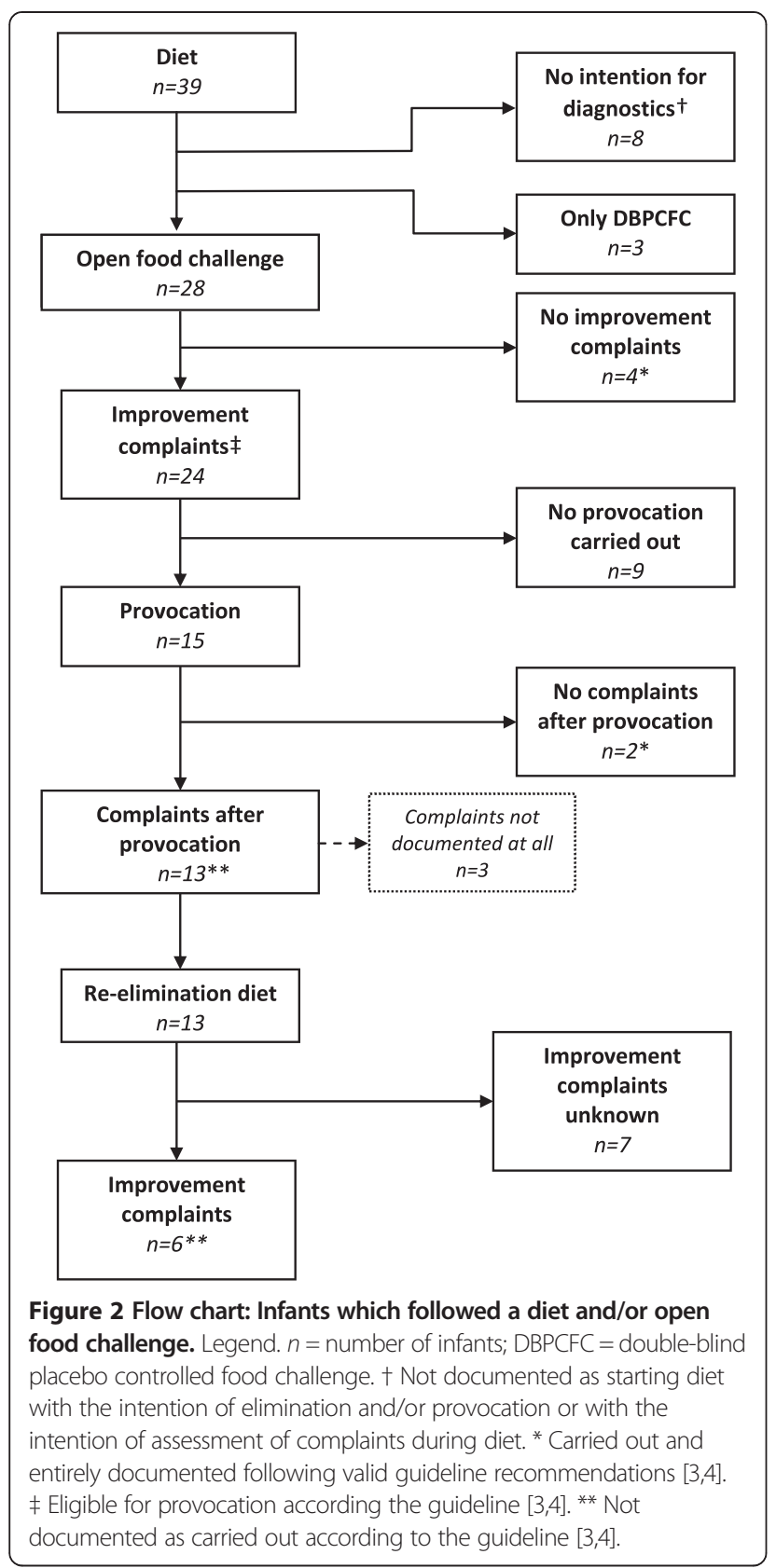

(b) not all test phases were (completely) performed, and (c) appearance or disappearance of complaints in the several phases of OFC was not documented. In summary, none of the infants had a positive DBPCFC or OFC entirely reported as performed according the guideline (Figure 2) [3].

\section{Dietary measures}

A milk substitute formula was prescribed in 39 infants (3\% whey hydrolysates milk formulas, $72 \%$ caseïne hydrolysates milk formulas, 3\% aminoacid based milk formulas and $21 \%$ breast milk with an elimination diet for the mother). A third of the infants (33\%) had used more than one type of milk substitute formulas. Duration of used dietary measures was not clear due to insufficient detailed information in both records.

\section{Discussion}

\section{Summary}

The prevalence of $7 \%$ for a suspicion of CMA found in the present study is 2-7 times higher compared with prevalence figures from previous studies assessing the prevalence of "diagnosed CMA" (ranging from $<1 \%$ to $3.5 \%)[1,2]$. We showed that a suspicion of CMA is a common problem in general practice, and that there is room for improvement of implementation and reporting of CMA diagnostics (none of the infants had a confirmed CMA diagnosis after a challenge test performed and reported according to Dutch national guideline recommendations).

\section{Guideline adherence}

CMA OFC test results were often difficult to interpret because the indication, implementation and reporting of diagnostics did not follow the current Dutch national guideline recommendations [3]. Therefore, the prevalence and health care burden of true (i.e. adequately confirmed) CMA in general practice was impossible to establish in this study. A possible explanation for common non-adherence to the definition of CMA suspicion could be parents who might be demanding towards their GP, insisting on additional diagnostic testing for CMA. However, in just a few cases (7\%) the suspicion of CMA was brought up solely by parents. In nearly all cases $(82 \%)$ the GP recorded that he or she at least shared the suspicion and acted accordingly.

\section{Limitations}

By using a selection of ICPC-1 codes that could possibly prompt a suspicion of CMA (Table 1) it is not inconceivable that a small number of relevant GP visits may have been missed. Unfortunately, CMA symptom ICPC code screening could only be performed for GP electronic records, and not for $\mathrm{PCH}$ records since a digital coding system is not available for their records. It is, however, unlikely that suspected cases were missed, since children with a possible CMA presenting to their $\mathrm{PCH}$ professional are likely to present also to the GP, and if not the $\mathrm{PCH}$ professionals by protocol will inform the GP in writing of any CMA diagnostics being performed, which will then be coded by the GP in the electronic system. Besides we could not assess the total amount of dietary formula prescribed. We could assess the percentage of children using prescribed milk substitute formulas (71\% of suspected children), though the duration of such formula use we could not evaluate resulting the 
lack of information in the records. Finally, our study was performed in four healthcare centers ( 23 GPs) in one central region of the Netherlands, possibly restricting generalizability of results.

\section{Implications}

Prevalence data can be used for further development of health care policy and intervention studies. Our results show that a suspicion of CMA is common in general practice, and that diagnosing and reporting of CMA work-up needs to be improved. The recently issued multidisciplinary guideline for diagnosing CMA in the Netherlands can contribute when completely implemented [6]. Implementation in $\mathrm{PCH}$ is currently in progress [13]. Remaining questions to be addressed include possible explanations for non-adherence in the diagnosis of CMA, its consequences and what needs to be further done to improve these results.

\section{Conclusion}

Suspected CMA is a common reason for consultation in primary care in the four Utrecht healthcare centers included in our study, with a prevalence of $7 \%$. Current management, in particular the diagnostic part, is not according to professional guidelines and dietary measures are prescribed often for a long time but not evaluated appropriately.

\section{Competing interests}

The authors declare that they have no competing interests.

\section{Authors' contributions}

NdW directed the study design and data collection. SvdH drafted the manuscript and contributed to all other aspects of the study. CvK and AvdP coordinated data collection and AvdP coordinated drafting the manuscript. CVK helped collecting the data and participated in writing the manuscript. YM and JT participated in the design of the study and helped draft the manuscript. All authors read and approved the final manuscript.

\footnotetext{
Author details

'Julius Center for Health Sciences and Primary Care, University Medical Center Utrecht, Room Str 6.131 Postbus 85500, 3508 Utrecht, GA, The Netherlands. ${ }^{2}$ Department of Paediatric Pulmonology and Allergology, University Medical Center Utrecht, Utrecht 3508 AB, The Netherlands. ${ }^{3}$ Department of Health Promotion \& Epidemiology, Municipal Health Services Utrecht, Utrecht 3521 AN, The Netherlands. ${ }^{4}$ Preventive Child Health Care, Municipal Health Services Utrecht, Utrecht 3521 AN, The Netherlands.
}

Received: 14 July 2014 Accepted: 30 July 2014

Published: 9 August 2014

\section{References}

1. Chafen JJ, Newberry SJ, Riedl MA, Bravata DM, Maglione M, Suttorp MJ, Sundaram V, Paige NM, Towfigh A, Hulley BJ, Shekelle PG: Diagnosing and managing common food allergies. JAMA 2010, 303(18):1848-1856.

2. Fiocchi A, Brozek J, Schünemann H, Bahna SL, von Berg A, Beyer K, Bozzola M, Bradsher J, Compalati E, Ebisawa M, Guzmán MA, Li H, Heine RG, Keith P, Lack G, Landi M, Martelli A, Rancé F, Sampson H, Stein A, Terracciano L, Vieths S: World Allergy Organization (WAO) Diagnosis and Rationale for Action against Cow's Milk Allergy (DRACMA) Guidelines. Pediatr Allergy Immunol 2010, 21(Suppl 21):1-125.

3. Lucassen P, Albeda F, van Reisen M, Silvius A, Wensing C, Luning-Koster M: NHG-Standaard Voedselovergevoeligheid. Huisarts Wet 2010, 53(10):537-553.
4. Lucassen PLBJ, de Vries-van Oostveen AS, Niebuur HKM, Smeenk RCJ, Stolk PW, van Moorsel RPM, Eizenga WH, Burgers JS: NHG-Standaard Voedselovergevoeligheid bij zuigelingen. Huisarts Wet 1995, 38:178-184.

5. Venter C, Pereira B, Grundy J, Clayton CB, Roberts G, Higgins B, Dean T: Incidence of parentally reported and clinically diagnosed food hypersensitivity in the first year of life. J Allergy Clin Immunol 2006 117(5):1118-1124.

6. Vlieg-Boerstra BJ, Wensing CL, Kneepkens CM, Meijer Y, de Vries E, Sprikkelman $A B$ : One guideline for diagnosing cow milk allergy; for primary, secondary and tertiary care in the Netherlands. Ned Tijdschr Geneeskd 2013, 157:A6311.

7. Kneepkens CMF, Meijer Y: Clinical practice. Diagnosis and treatment of cow's milk allergy. Eur J Pediatr 2009, 168(8):891-896.

8. Sladkevicius E, Guest JF: Budget impact of managing cow milk allergy in the Netherlands. J Med Econ 2010, 13(2):273-283.

9. Sladkevicius E, Nagy E, Lack G, Guest JF: Resource implications and budget impact of managing cow milk allergy in the UK. J Med Econ 2010, 13(1):119-128.

10. National Institute for Health and Care Excellence (2011): [Food Allergy in Children and Young People], [CG116]. London: National Institute for Health and Care Excellence; 2011.

11. Wistudata online database containing figures of Utrecht city. In [http://utrecht.buurtmonitor.nl/]

12. Bentsen BG: International classification of primary care. Scand J Prim Health Care 1986, 4(1):43-50.

13. Dutch center preventive child health care. In [https://www.ncj.nl/ programmalijn-kennis/landelijke-werkdocumenten/richtlijn/?item=84]

doi:10.1186/1756-0500-7-507

Cite this article as: van den Hoogen et al: Suspected cow's milk allergy in everyday general practice: a retrospective cohort study on health care burden and guideline adherence. BMC Research Notes 2014 7:507.

\section{Submit your next manuscript to BioMed Central and take full advantage of:}

- Convenient online submission

- Thorough peer review

- No space constraints or color figure charges

- Immediate publication on acceptance

- Inclusion in PubMed, CAS, Scopus and Google Scholar

- Research which is freely available for redistribution 